\title{
Difference of Curcumin Content in Curcuma longa L. (Zingiberaceae) Caused by Hybridization with Other Curcuma Species
}

\author{
Hiroshi Hayakawa ${ }^{1,2}$, Yukio Minaniya ${ }^{1}$, Katsura Ito ${ }^{1}$, Yoshinori Yamamoto ${ }^{1}$, Tatsuya Fukuda ${ }^{1}$ \\ ${ }^{1}$ Faculty of Agriculture, Kochi University, Nankoku, Japan; ${ }^{2}$ United Graduate School of Agricultural Sciences, Ehime University, \\ Nankoku, Japan. \\ Email: tfukuda@kochi-u.ac.jp
}

Received November $29^{\text {th }}, 2010$; revised January $24^{\text {th }}, 2011$; accepted January $30^{\text {th }}, 2011$.

\begin{abstract}
Curcumin, which is traditionally known to have effects on various types of diseases in humans, is found in Curcuma longa L. Previous reports have indicated that the curcumin content varies between the different lines of this species. To clarify the differences in the amounts of curcumin between the lines, we investigated the outcomes of cultivation experiments with the hybridization or introgression between C. longa and other Curcuma species using the matK gene of chloroplast DNA ( there is heterogeneity of the ETS and incongruence between the matK and the ETS phylogenetic trees, suggesting that hybridization and introgression had taken place in the diversification of the various lines of C. longa. Moreover, although all of the lines had the same cpDNA haplotype of C. longa, the lines of homogeneous C. longa had a high content of curcumin, whereas the lines created by hybridization and introgression with other Curcuma species had a medium or low level. These results suggest that the difference of curcumin content among the various lines of C. longa was caused by hybridization and introgression with other Curcuma species.
\end{abstract}

Keywords: Curcuma longa, Curcumin, Hybridization, Introgression, Molecular Analysis, Nuclear DNA

\section{Introduction}

Many chemicals in plants are potential drugs for humans and natural products from plants are found in many therapeutic formulations. Moreover, conscious efforts to search for desirable traits in plants have been underway for the past century, and in recent decades species with desirable traits have come to be regarded as important biological resources in need of conservation [1].

Curcuma longa L., which belongs to the ginger family, Zingiberaceae, is a perennial widely used as a spice, a colorant and also as a major ingredient of curry powder [2]. This species has a long history of use as a traditional medicine in China and India [3], reflecting it's diverse and beneficial health effects. In addition, the curcuma species contains phenolic compounds found in the plant's rhizomes. Traditionally, curcumin is well-known to have therapeutic effects on a variety of human diseases, and the cancer preventive activity of curcumin is being intensively studied all over the world. Experiments in animal models indicate that it is a preventive agent against vari- ous types of cancer [4]. Specifically, curcumin inhibits the cell growth of various cancer cell lines, induces apoptosis of cancer cells [5-7], and was effective on the cell-cycle regulation of cancer cells [8].

According to previous study there is a difference in the curcumin content among individuals of C. longa $[9,10]$, however, it remains unclear why the curcumin content is different. To identify the lines with high curcumin content, Hayakawa et al. [10,11] developed a molecular marker. Recent molecular phylogenetic study using chloroplast DNA (cpDNA) sequences indicated that $C$. longa has some closely related species. Also, a large number of previous studies of species within the genus Drosophila had illuminated the relationship between genetic distance and reproductive isolation $[12,13]$. One possibility is that the difference in curcumin content within C. longa was caused by including hybrids between C. longa and other Curcuma species. It is very difficult to detect polymorphisms of morphology of the rhizomes and cpDNA sequences within this species. Al- 
though this hypothesis could be clarified by comparing nuclear DNA (nrDNA) sequences, unfortunately, such study has not been done so far.

The number of phylogenetic studies based on molecular data has grown enormously in recent years, and most of the recent studies are concerned with closely related species or variation within species. In particular, the use of molecular markers has considerably improved our knowledge about how past events shape the genetic diversity within a species [14-16]. Recently, various molecular markers have been widely analyzed to assess the genetic variability of wild plants [17]. Among them, nuclear markers are mostly neutral with relatively high mutation rates, and, in association with the history, provide information to estimate the putative parents involved in hybridization and introgression [18,19]. The polymorphisms of the external transcribed spacer (ETS) region in nuclear DNA (nrDNA) are good tools for clarifying the relationship of closely related taxa in many plant groups
[20-24]. Here, to test our hypothesis of the hybridization of C. longa, we describe the DNA polymorphisms of the ETS region in C. longa and its allied species and discuss the possible reasons for the differences in curcumin content of this species.

\section{Materials and Methods}

\subsection{Plant Materials}

For the plant materials, we used 1 Curcuma alismatifolia Gagnep. cultivar 'Sawang Chiang Mai', 3 C. aromatica Salib., 12 C. longa L. and 1 C. zedoaria Rosc. for molecular analysis in this study (Table 1). Of these, 2 C. aromatica, 5 to 12 C. longa and 1 C. zedoaria were cultivated in the field of the Faculty of Agriculture, Kochi University, Japan for 2006-2009 (See detail Hayakawa et al. [10]). Rhizomes were transplanted in late May for four years. For fertilizer dressing, a total of $1.5 \mathrm{~kg} / \mathrm{a}$ of N, $0.6 \mathrm{~kg} / \mathrm{a}$ of $\mathrm{P}_{2} \mathrm{O}_{5}$, and $1.4 \mathrm{~kg} / \mathrm{a}$ of $\mathrm{K}_{2} \mathrm{O}$ was applied over

Table 1. List of sample of Curcuma species used in this study.

\begin{tabular}{|c|c|c|c|c|c|c|}
\hline \multirow{2}{*}{ No. Sepcies } & \multirow{2}{*}{ Locality } & \multicolumn{4}{|c|}{ Curcumin content ${ }^{1}$} & \multirow{2}{*}{$\begin{array}{l}\text { nrDNA }^{3} \\
\text { Type }\end{array}$} \\
\hline & & 2006 & 2007 & 2008 & 2009 & \\
\hline $\begin{array}{l}1 \text { Curcuma alismatifolia 'Sawang Chiang } \\
\text { Mai' }\end{array}$ & Chiang Mai. Thailand & $--^{2}$ & - & - & - & \\
\hline 2 C. aromatica (Kochi) & Kochi Perfecture. Japan & $38^{\mathrm{bcd}}$ & $71^{\mathrm{b}}$ & $47^{\mathrm{b}}$ & $126^{\mathrm{c}}$ & \\
\hline 3 C. aromatica (Tanegashima) & $\begin{array}{l}\text { Tanegashima Island. Kagoshima Perfecture. } \\
\text { Japan }\end{array}$ & $41^{\text {abcd }}$ & $78^{\mathrm{bc}}$ & $36^{\mathrm{b}}$ & $122^{\mathrm{c}}$ & \\
\hline 4 C. aromatica (Okinawa) & Okinawa Perfecture. Japan & - & - & - & - & \\
\hline 5 C. longa (Kochi) & Kochi Perfecture. Japan & $327^{\mathrm{ab}}$ & $398^{\mathrm{ab}}$ & $358^{\mathrm{ab}}$ & $392^{\mathrm{c}}$ & Hybrid \\
\hline 6 C. longa (Tanegashima) & $\begin{array}{l}\text { Tanegashima Island. Kagoshima Perfecture. } \\
\text { Japan }\end{array}$ & $301^{\mathrm{abc}}$ & $382^{\mathrm{ab}}$ & $392^{\mathrm{ab}}$ & $361^{\mathrm{c}}$ & Hybrid \\
\hline 7 C. longa (Wakayama A) & Wakayama Perfecture. Japan & $179^{\mathrm{abcd}}$ & $403^{\mathrm{ab}}$ & $388^{\mathrm{ab}}$ & $374^{\mathrm{c}}$ & Hybrid \\
\hline 8 C. longa (Wakayama B) & Wakayama Perfecture. Japan & $1^{\mathrm{d}}$ & $2^{\mathrm{c}}$ & $1^{\mathrm{b}}$ & $1^{\mathrm{c}}$ & Introgression \\
\hline 9 C. longa (Wakayama C) & Wakayama Perfecture. Japan & - & $404^{\mathrm{abc}}$ & $396^{\mathrm{ab}}$ & $390^{\mathrm{c}}$ & Hybrid \\
\hline 10 C. longa (Okinawa A) & Okinawa Perfecture. Japan & - & - & $364^{\mathrm{ab}}$ & $347^{\mathrm{c}}$ & Hybrid \\
\hline 11 C. longa (Okinawa B) & Okinawa Perfecture. Japan & - & - & $373^{\mathrm{ab}}$ & $305^{\mathrm{c}}$ & Hybrid \\
\hline 12 C. longa (Indonesia A) & Bogol. West Java. Indonesia & $2849^{\mathrm{a}}$ & $2777^{\mathrm{a}}$ & $2678^{\mathrm{a}}$ & $3059^{\mathrm{a}}$ & Pure line \\
\hline 13 C. longa (Indonesia B) & Bogol. West Java. Indonesia & - & $229^{\mathrm{abc}}$ & $337^{\mathrm{ab}}$ & $310^{\mathrm{c}}$ & Hybrid \\
\hline 14 C. longa (Indonesia C) & Bogol. West Java. Indonesia & - & - & - & $2315^{\mathrm{b}}$ & Pure line \\
\hline 15 C. longa (Vietnam A) & Vietnam & - & - & - & $2977^{\mathrm{a}}$ & Pure line \\
\hline 16 C. longa (Vietnam B) & Vietnam & - & - & - & $3198^{\mathrm{a}}$ & Pure line \\
\hline 17 C. zedoaria & Unkonwn & $1^{\mathrm{cd}}$ & $2^{\mathrm{c}}$ & $1^{\mathrm{b}}$ & $1^{\mathrm{c}}$ & \\
\hline
\end{tabular}

${ }^{1}$ Curcumin content in primaly branch rhizomes $(\mathrm{mg} / 100 \mathrm{~g}){ }^{2}$ Not examind. ${ }^{3}$ Type of nrDNA in Curcuna longa. Values followed by the same latter in a column of each year are not signigicantly at $5 \%$ level by one-way ANOVA. 
four years. In addition, $200 \mathrm{~kg} / \mathrm{a}$ of compost fertilizer, 15 $\mathrm{kg} / \mathrm{a}$ of magnesia lime, and $30 \mathrm{~kg} / \mathrm{a}$ of chicken droppings were applied. The experimental plots were arranged in a randomized complete design with two replicates, which formed three rows. Due to a lack of seed rhizomes, some lines of $C$. longa were examined with/without replicate using two or three rows. Samples were harvested in early December for four years. The total curcumin content (mg/100g) of primary branch rhizomes was measured by using High Performance Liquid Chromatography (HPLC), according to the method described by Sato et al. [25].

\subsection{Molecular Analyses}

For the molecular analyses, total DNA was isolated from fresh root using a Plant Genomic DNA Mini Kit (VIOGENE, Sunnyvale, USA), according to the manufacturer's protocol. We amplified the maturase $K$ (matK) gene from cpDNA and the external transcribed spacer (ETS) region of 18S-26S rDNA from nrDNA with primers designed by Johnson and Soltis [26] and Starr et al. [27], respectively. The isolated DNA was amplified by PCR in a $50 \mu$ l reaction solution containing approximately $50 \mathrm{ng}$ total DNA, $10 \mathrm{mM}$ Tris- $\mathrm{HCl}$ (pH 8.3), 50 $\mathrm{mM} \mathrm{KCl}, 1.5 \mathrm{mM} \mathrm{MgCl}_{2}, 0.2 \mathrm{mM}$ of each dNTP, 1.25 units Taq DNA polymerase (TaKaRa) and $0.5 \mu \mathrm{M}$ of each primer pair. We used the following thermal cycle profile for amplification by the PCR Thermal Cycler Dice (TaKaRa): $1 \mathrm{~min}$ at $94^{\circ} \mathrm{C}, 2 \mathrm{~min}$ at $48^{\circ} \mathrm{C}$, and $2 \mathrm{~min}$ at $72^{\circ} \mathrm{C}$ for 45 cycles, followed by $15 \mathrm{~min}$ of final extension at $72^{\circ} \mathrm{C}$. After amplification, the PCR products of the $m a t K$ and ETS region were subjected to electrophoresis in $1 \%$ low-melting-temperature agarose gels to remove by-products and purify amplified products. We sequenced the purified PCR products using a BigDye Terminator ver. 3.1 (Applied BioSystems) and ABI Prism 3100 Genetic Analyzer (Applied BioSystems) according to the manufacturer's instructions. For sequencing, we used the same primers as those used for amplification.

To construct a phylogenetic tree based on the matK sequences of Curcuma and its allied species and the ETS sequences of Curcuma species, the amplified regions were aligned using ClustalW [28] and were improved manually using MEGA 4 [29]. Phylogenetic relationships were analyzed using the neighbor-joining (NJ) method with PAUP* 4.08b [30]. The NJ analyses were performed using MEGA 4 with Kimura's two-parameter model. For the NJ analyses, bootstrapping with 1000 pseudo-replicates was chosen to examine the robustness of the clades and their phylogenetic relationships. The matK sequences were collected from DDBJ/EMBL/ GenBank International DNA databases (Table 2).

For the ETS region, because $C$. longa with a medium curcumin content could not determine its sequence caused by putative heterozygosity, we carried out PCRRFLP analysis after checking the sequencing results and alignments. The result of the alignments indicated that an autapomorphic character of the nrDNA was the restriction site Hinf I. After designating the restriction sites, the amplified products were digested by Hinf I at $37^{\circ} \mathrm{C}$ for more than an hour. The digested DNAs were separated on $1.0 \%$ agarose gel and the size of each band was determined.

\section{Results}

\subsection{Curcumin Content}

The gradient of curcumin content between species decreased as follows; South Asian C. longa $>$ domestic $C$. longa and $C$. longa (Indonesia B) $>C$. aromatica $>C$. zedoaria and C. longa (Wakayama B) (Table 1) [10] and the level of curcumin content was divided into three groups; high, medium and low.

\subsection{Molecular Analyses}

To construct the molecular phylogenetic tree of Curcuma and its allied species, we determined the sequences of the matK gene of Curcuma cpDNA and seven outgroup taxa (Table 2). The lengths of the matK gene of the Curcuma species varied from 1539 bp (C. alismatifolia 'Sawang Chiang Mai' and C. longa (Wakayama B)) to 1554 bp (C. thorelii). The result of the phylogenetic analysis of matK indicated that $C$. longa had a conserved sequence in this species and was closely related to C. aromatica and $C$. zedoaria, whereas C. alismatifolia 'Sawang Chiang Mai' was located in the basal position of the phylogenetic tree and the sister to $C$. thorelii with a high boot strap value (Figure 1).

In addition, we sequenced the ETS region of nrDNA to detect polymorphisms among Curcuma species. The lengths of the ETSs of Curcuma species were 514 bp (C. alismatifolia) to $517 \mathrm{bp}$ (C. aromatica). The sequences have been deposited into the DDBJ/EMBL/GenBank International DNA databases (C. alismatifolia, AB588183; C. aromatica: AB588181, C. longa: AB588182, AB588185 and AB588186, C. zedoaria: AB588184). The results of the phylogenetic analyses of the ETSs indicated that $C$. longa and closely related species were divided into two monophyletic groups: clade 1 and clade 2 (Figure 2). Clade 1 consisted of all individuals of $C$. longa and clade 2 consisted of C. longa, C. aromatica and C. zedoaria. Although all homogeneous C. longa with its high curcumin content appeared in clade $1, C$. longa (Wakayama B) with its low curcumin content was located in clade 2 (Figure 2, Table 1). This suggested 
Table 2. Accession numbers of matK using phylogenetic analysis of Curcuma and outgroup taxa.

\begin{tabular}{|c|c|c|}
\hline \multirow[b]{2}{*}{ Species } & \multicolumn{2}{|r|}{ matK } \\
\hline & Accession No. & Reference \\
\hline Curcuma aeruginosa & AF478840 & Kress et al. (2002) \\
\hline C. amarissima & AB047751 & Cao et al. (Unpubl.) \\
\hline C. alismatifolia 'Sawang Chiang Mai' & AB588187 & this study \\
\hline C. aromatica & AB047731 & Cao et al. (2001) \\
\hline C. aromatica (Kochi) & AB551929 & Hayakawa et al. (2010) \\
\hline C. aromatica (Tanegashima) & AB551929 & Hayakawa et al. (2010) \\
\hline C. aromatica (Okinawa) & AB551929 & Hayakawa et al. (2010) \\
\hline C. attenuata & GQ248110 & Hollingsworth et al. (Unpubl.) \\
\hline C. bicolor & AF478837 & Kress et al. (2002) \\
\hline C. chuanezhu & AB047736 & Cao et al. (2001) \\
\hline C. chuanhuangjiang & AB047732 & Cao et al. (2001) \\
\hline C. chuanyujin & AB047733 & Cao et al. (2001) \\
\hline C. comosa & AF478838 & Kress et al. (2002) \\
\hline C. elata & AB047747 & Cao et al. (Unpubl.) \\
\hline C. exigua & $\mathrm{AB} 047750$ & Cao et al. (Unpubl.) \\
\hline C. kwangsiensis A & AB047744 & Cao et al. (2001) \\
\hline C. kwangsiensis B & AB047745 & Cao et al. (Unpubl.) \\
\hline C. longa (Kochi) & AB551930 & Hayakawa et al. (2010) \\
\hline C. longa (Tanegashima) & AB551930 & Hayakawa et al. (2010) \\
\hline C. longa (Wakayama A) & AB551930 & Hayakawa et al. (2010) \\
\hline C. longa (Wakayama B) & AB551931 & Hayakawa et al. (2010) \\
\hline C. longa (Wakayama C) & AB551930 & Hayakawa et al. (2010) \\
\hline C. longa (Okinawa A) & AB551930 & Hayakawa et al. (2010) \\
\hline C. longa (Okinawa B) & AB551930 & Hayakawa et al. (2010) \\
\hline C. longa (Indonesia A) & AB551930 & Hayakawa et al. (2010) \\
\hline C. longa (Indonesia B) & AB551930 & Hayakawa et al. (2010) \\
\hline C. longa (Indonesia C) & AB551930 & Hayakawa et al. (2010) \\
\hline C. longa (Vietnam A) & AB551930 & Hayakawa et al. (2010) \\
\hline C. longa (Vietnam B) & AB551930 & Hayakawa et al. (2010) \\
\hline C. longa & AB047738 & Cao et al. (2001) \\
\hline C. phaeocaulis & AB047735 & Cao et al. (2001) \\
\hline C. roscoeana A & AB047741 & Cao et al. (Unpubl.) \\
\hline C. roscoeana B & AF478839 & Kress et al. (2002) \\
\hline C. sichuanensis A & AB047739 & Cao et al. (Unpubl.) \\
\hline C. sichuanensis B & AB047740 & Cao et al. (Unpubl.) \\
\hline C. thorelii & AF478841 & Kress et al. (2002) \\
\hline C. wenyujin & AB047746 & Cao et al. (2001) \\
\hline C. xanthorrhiza & AB047752 & Cao et al. (Unpubl.) \\
\hline C. yunnanensis & AB047749 & Cao et al. (Unpubl.) \\
\hline C. zedoaria & AB551932 & Hayakawa et al. (2010) \\
\hline C. zedoaria A & AB047734 & Cao et al. (2001) \\
\hline C. zedoaria B & AB047743 & Cao et al. (2001) \\
\hline \multicolumn{3}{|l|}{ Outgroup } \\
\hline Boesenbergia rotunda & AF478827 & Kress et al. (2002) \\
\hline Cautleya spicata & AF478834 & Kress et al. (2002) \\
\hline Cornukaempferia aurantiflora & AF478835 & Kress et al. (2002) \\
\hline Curcumorpha longiflora & AF478842 & Kress et al. (2002) \\
\hline Kaempferia marginata & AB232054 & Sitthithaworn and Komatsu (Unpubl.) \\
\hline Scaphochlamys biloba & AF478889 & Kress et al. (2002) \\
\hline Zingiber mioga & AB047755 & Cao et al. (Unpubl.) \\
\hline
\end{tabular}




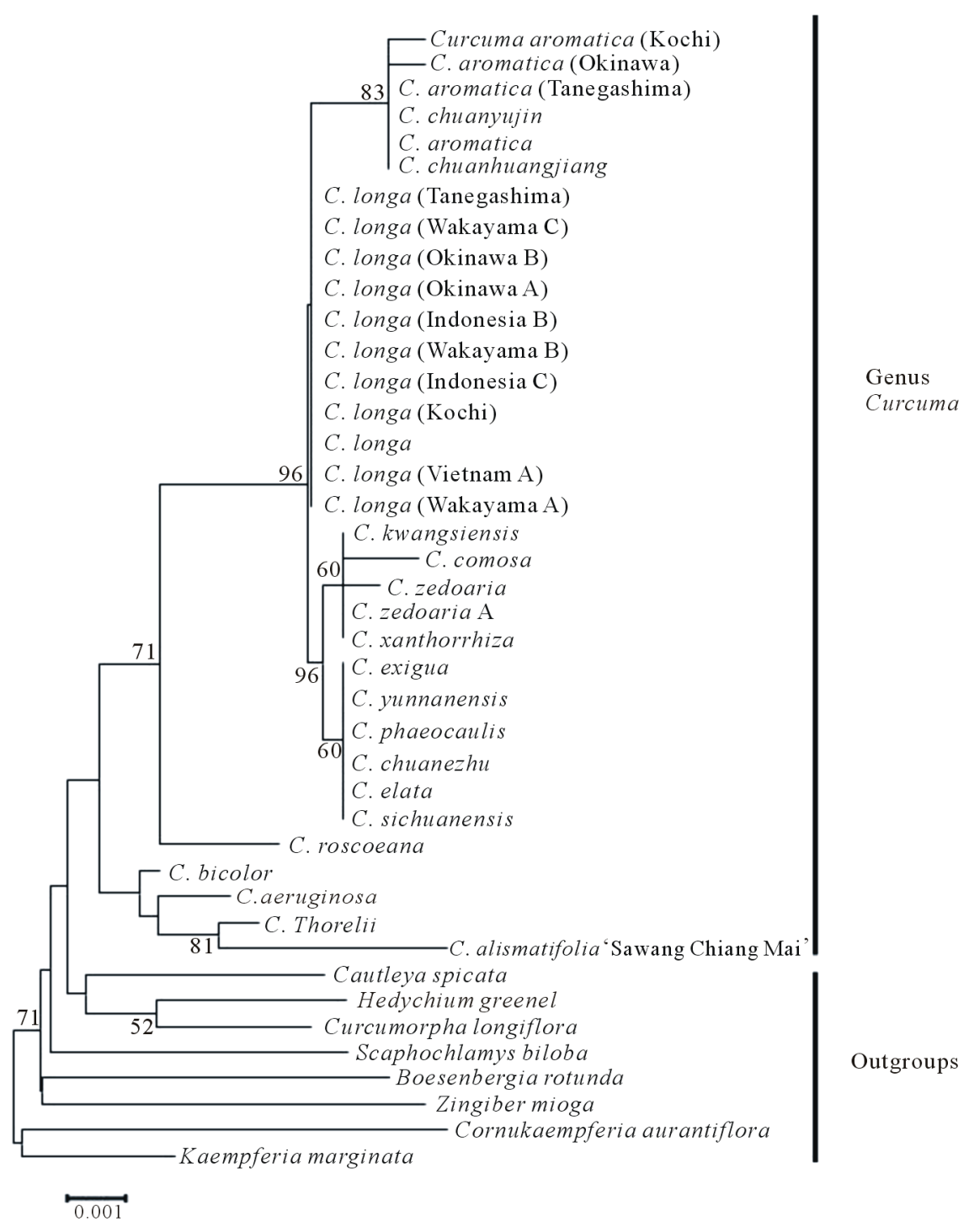

Figure 1. Phylogenetic tree of Curcuma and its allied species in the matK gene of cpDNA using the neighbor-joining (NJ) method. The numbers below the branches indicate the bootstrap value.

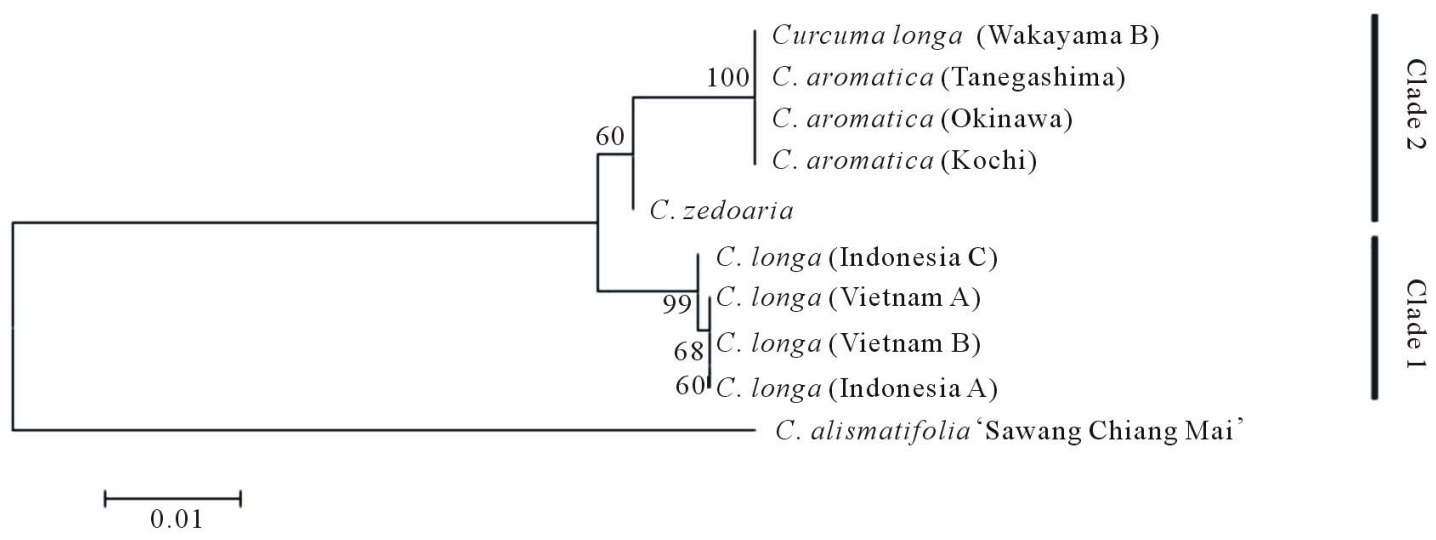

Figure 2. Phylogenetic tree of Curcuma species in the ETS region of nrDNA using the NJ method. The numbers below the branches indicate the bootstrap value. 
that C. longa (Wakayama B) was introgressive with clade 2 because it had the cpDNA haplotype of $C$. longa. However, some individuals could not be sequenced in the ETS region because of the putative heterogeneity of $C$. longa and other Curcuma species. To detect their heterogeneity, we conducted a PCR-RFLP analysis because restriction of the site of Hinf I to distinguish C. longa with other Curcuma species was in the ETS region (Figure 3). The result was that the digestion pattern of all samples of homogeneous $C$. longa and C. aromatica showed the expected patterns, and heterogeneous $C$. longa showed the combined patterns of homogeneous $C$. longa and C. aromatica (Figure 4). Moreover, C. longa (Wakayama B) showed same band pattern as C. aromatica. We therefore confirmed that the medium and low curcumin contents of $C$. longa were hybrid and introgressive between C. longa and other Curcuma species on clade 2 (Figure 4, Table 1).

\section{Discussion}

In general, hybrids typically display a mosaic of parental and intermediate morphological characters, although extreme and novel characters appear quite often. A species with morphological characteristics intermediate between two recognized species has always been considered to be a hybrid [31]. However, morphological characteristics alone, such as the rhizomes of the Curcuma species, are of limited value when identifying natural hybrids, but molecular studies have greatly enhanced our knowledge in this field [32]. Interspecific hybrids are most commonly identified by the heterogeneity of nrDNA and the incongruences between cpDNA and nrDNA phylogenies that may indicate different parental contributions to the hybrid genome [33,34]. In particular, incongruence between cpDNA and nrDNA phylogenies is very likely the result of interspecific gene flow and subsequent

\section{C. longa \\ C. aromatica}

C. longa

C. aromatica

C. longa

C. aromatica

C. longa

C. aromatica

C. longa

C. aromatica

C. longa

C. aromatica

C. longa

C. aromatica

C. longa

C. aromatica

C. longa

C. aromatica

C. longa

C. aromatica
TGAAGGGCACATTGCCGTCATGCGGCTATT TGCATCGTCTCTGAGGCTTTTTCATCTGTC

TGAAGGGCACATTGCCGTCA TGCGGCTATT TGCATCGTCTCTGAGGCTTTTTCATCTGTC

GCCTACTCGTGTTATATTTTCGAGT TGTGGGTGTTGCT TGTGCTATATGCTCTCGTTCCA

GCCTACTCGTGTTATATTTTCGAGT TGTGGGTGTTGCT TGTGCTATATGCTCTCGTTCCA

AGGAAAATGAGCACTTTTCTGACAAAGACATTCCCTCCGATTGTTATGGGGAGTTTGGAG

AGGAAAATGAGCACTTTTCTGACAAAGACATTCCCTCCGATTGTCATGCGGAGT TTGGAG

TGAAAATTCATTTGATCTGTGTTCTCTTCACGGATGTTGTCCTTGACACATCC-GCTGGG

TGAAAATTCATTTGATCCGTGT TCTCTTCATGGATGTTGTCCTTGACACATCCCGCTGGA

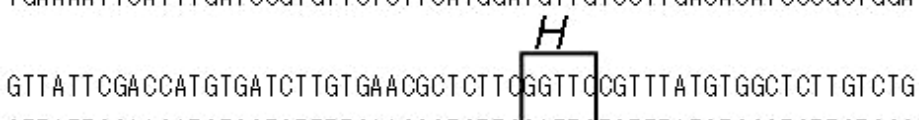

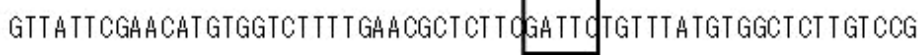

GCCCTCGGGCTTAGACGTTCGGATTGGCATCGCTCTCTTGCAGTAGCGCTTGCCTTCGTA

GCCCTCGGGCGTAGACGTTCGGATTGGCATCGCTCTCTTGCAGT AGCGCTTGCCTTCGTA

ACT TGGGTTCGAAGCTGCTCTCTCAGCCCACT TGCCTTGTTGCTTCTCGTTGGGGTTGCG

ACTTGGGTTCGAAGCTGCTCTCTCAGCCCACT TGCCTTGTTGCTTCTCGTTGGGGTTGCG

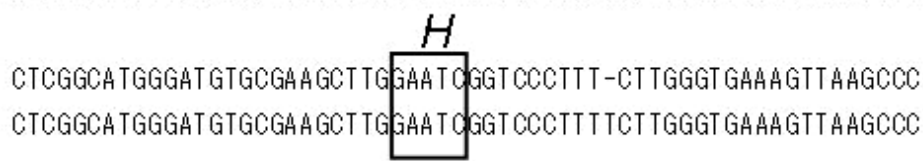

CCTAGCACT TGCTCGCCTCATGGTCGGCTATTGCTGTGATGGGCTCTATGT TCGGAAGAT

CCTAGCACT TGCTCGCCTCATGGTCGGCTATTGCTGTGATGGGCTCTATGTTTGAAAGAT

ATGT TGCCTGGTTGATCCTGCCAGTAG

ATGTTGCCTGGTTGATCCTGCCAGTAG

Figure 3. Expected restriction sites of Hinf I for molecular characteristics of ETS regions by PCR-RFLP. H: restriction site. 


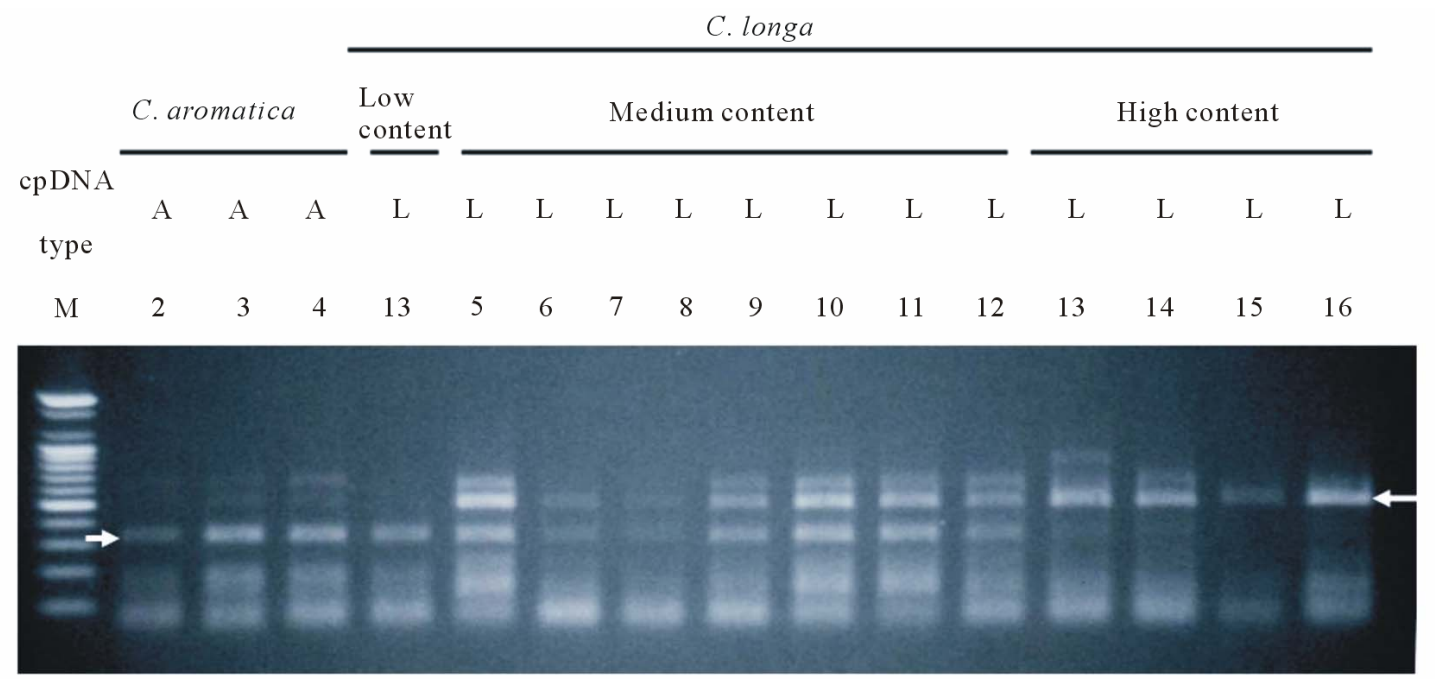

Figure 4. PCR-RFLP profile of various lines of $C$. longa and $C$. aromatica. Arrows indicate expected fragments of both $C$. longa and C. aromatica. M: size marker. A: C. aromatica. L: C. longa. Plant number corresponds to the numbers in Table 1.

chloroplast capture. In fact, some studies indicate that introgression and asymmetric capture of the cpDNA are common phenomena in hybridized species [19,35]. Our results indicated that hybrid and introgressive individuals with other Curcuma species were included in C. longa although hybrid and introgressive have same haplotype of C. longa based on matK sequences of cpDNA (Figure 1). Moreover, it is very interesting that homogeneous $C$. longa has a high curcumin content, and that a heterogeneous hybrid of the Curcuma genome has a medium amount of curcumin. Additionally, an introgressive sample with incongruent haplotypes between cpDNA and nrDNA has a low content of curcumin (Table 1, Figure 4). Therefore, the pattern of decreased curcumin content was congruent with the hybridization or introgression between $C$. longa and other Curcuma species, such as $C$. aromatica, which have low curcumin content. These results indicated that hybridization or introgression with other Curcuma species could affect the content of curcumin of $C$. longa. In this study, $C$. longa proved to be the seed parent of the hybrid and introgression samples because all of the haplotypes on the matK of cpDNA matched this species. In the future, an analysis of the curcumin content of hybrid and introgression samples in which $C$. longa is the pollen parent needs to be conducted. In addition, the recent resurgence in plant development study has been accelerated, in part, by success in elucidating the molecular genetic basis of plant developmental processes, including the isolation and characterization of genes that synthesize curcumin in C. longa [36-38]. As a result of these studies, it is considered very important to isolate and analyze the homologous genes of C. longa apart from other Curcuma species. As for hy- brids, Allard [39] claimed that interspecific hybrids are very useful in introducing genetic divergence, and, in fact, hybrids have been used for many crops and ornamental plants. The way it was stated now appears that it is negating the well established knowledge of hybrid vigor and our results could not support this claim because interspecific hybrids contribute to the decrease in the curcumin content of C. longa.

Genetic variation is one of the fundamental underpinnings of biological diversity. The genetic structure and history of a given species is an important research focus, because this knowledge is needed to plan species conservation and to understand the evolutionary processes leading to diversity. Our study results suggest that reproductive isolation mechanisms were not acting in the case of the small phylogenetic distances among the Curcuma species (Figure 1). The evolution of reproductive isolation is one of the defining characteristics of speciation [40], and reproductive isolation contributes to the diversification of species by creating genetically independent lineages and phylogenetic tree branches [41]. Each branching of the tree is a speciation event; however, reproductive isolation alone does not create a new branch. Each branch by itself cannot produce the phenotypic divergence represented by the angular departure of a branch from the ancestral form [41]. Therefore, the diversification in the Curcuma species may have other factors involved rather than just reproductive isolation. In the future, it will be necessary to consider the phylogenetic implications in order to understand the detailed evolutionary history of the Curcuma species.

In summary, we have provided a hypothesis for the differences of curcumin by analyzing cpDNA and nrDNA 
data. Our results, using a molecular approach, were highly effective in revealing the histories of hybridization and introgression of C. longa. However, our data was less effective in definitively answering the question concerning the differences of curcumin content. Further studies will be needed to determine whether more comprehensive samplings and additional genetic evidence support the working hypothesis we have developed here.

\section{Acknowledgements}

We wish to thank T. Kobayashi, A. Miyazaki, R. Arakawa and J. Yokoyama. T. Yoshida, A. Matsuzawa, A. Hirata, Y. Muramatsu, M. Saito, R. Ueda, K. Ohga, N. Yokoyama, M. Muroi, and K. Matsuyama for providing much help. This study was partly supported by a grantin-aid for scientific research from the Ministry of Education, Science, and Culture of Japan (T.F.).

\section{REFERENCES}

[1] S. D. Tanksley and S. R. McCouch, "Seed Banks and Molecular Maps: Unlocking Genetic Potential from the Wild," Science, Vol. 277, No. 5329, 1997, pp. 1063-1066. doi:10.1126/science. 277.5329 .1063

[2] A. Asai and T. Miyazawa, "Dietary Curcuminoids Prevent High-Fat Diet-Induced Lipid Accumulation in Rat Liver and Epididymal Adipose Tissue," Journal of Nutrition, Vol. 131, No. 11, 2001, pp. 2932-2935.

[3] A. C. Beynen, J. J. Visser and J. A. Schouten, "Inhibitory Effect on Lithogenesis by Ingestion of a Curcuma Mixture (Temoe Lawak Singer)," Journal of Food Science Technology, Vol. 24, 1987, pp. 253-256.

[4] P. Anand, C. Sundaram, S. Jhurani, A. B. Kunnumakkara and B. B. Aggarwal, "Curcumin and Cancer: An 'Old-Age' Disease with an 'Age-Old' Solution," Cancer Letters, Vol. 267, No. 1, 2008, pp. 133-164. doi:10.1016/j.canlet.2008.03.025

[5] S. Aggarwal, Y. Takada, S. Singh, J. N. Myers and B. B. Aggarwal, "Inhibition of Growth and Survival of Human Head and Neck Squamous Cell Carcinoma Cells by Curcumin via Modulation of Nuclear Factor-Kb Signaling," International Journal of Cancer, Vol. 111, No. 5, 2004, pp. 679-692. doi:10.1002/ijc.20333

[6] Z. Wang, Y. Zhang, S. Banerjee, Y. Li and F. H. Sarkar, "Inhibition of Nuclear Factor Kappab Activity by Genistein is Mediated via Notch-1 Signaling Pathway in Pancreatic Cancer Cells," International Journal of Cancer, Vol. 118, No. 8, 2006, pp. 1930-1936. doi:10.1002/ijc. 21589

[7] N. M. Weir, K. Selvendiran, V. K. Kutala, L. Tong, S. Vishwanath, M. Rajaram, S. Tridandapani, S. Anant and P. Kuppusamy, "Curcumin Induces G2/M Arrest and Apoptosis in Cisplatin-Resistant Human Ovarian Cancer Cells by Modulating Akt and p38 MAPK," Cancer Biology and Therapy, Vol. 6, No. 2, 2007, pp. 178-184.

\section{doi:10.4161/cbt.6.2.3577}

[8] E. Liu, J. Wu, W. Cao, J. Zhang, W. Liu, X. Jiang and X. Zhang, "Curcumin Induces G2/M Cell Cycle Arrest in a p53-Dependent Manner and Upregulates Ing4 Expression in Human Glioma," Journal of Neuro-Oncology, Vol. 85, No. 3, 2007, pp. 263-270. doi:10.1007/s11060-007-9421-4

[9] K. Aoi, K. Kaburagi, T. Seki, T. Tobata, M. Sarak and M. Kuroyanagi, "Studies on the Cultivation of Turmeric (Curcuma longa L.) I: Varietal Differences in Rhizome Yield and Curcuminoid Content," Bulletin of National Institute of Hygiene Science, Vol. 104, 1986, pp. 124-128.

[10] H. Hayakawa, T. Kobayashi, Y. Minamiya, K. Ito, A. Miyazaki, T. Fukuda and Y. Yamamoto, "Development of a Molecular Marker to Identify a Candidate Line of Turmeric (Curcuma longa L.) with a High Curcumin Content," American Journal of Plant Siences, Vol. 2, No. 1, 2011, pp. 15-26. doi:10.4236/ajps.2011.21002

[11] H. Hayakawa, T. Kobayashi, Y. Minamiya, K. Ito, A. Miyazaki, T. Fukuda and Y. Yamamoto, "Molecular Identification of Turmeric (Curcuma longa, Zingiberceae) with a High Curcumin Content," Journal of Japanese Botany, Vol. 85, No. 5, 2010, pp. 263-269.

[12] J. A. Coyne and H. A. Orr, "Patterns of Speciation in Drosophila," Evolution, Vol. 43, No. 2, 1989, pp. 362381. doi: $10.2307 / 2409213$

[13] J. A. Coyne and H. A. Orr, "Patterns of Speciation in Drosophila Revisited," Evolution, Vol. 51, No. 1, 1997, pp. 295-333. doi:10.2307/2410984

[14] J. C. Avise, J. Arnold, R. M. Ball, E. Bermingham, T. Lamb, J. E. Neigel, C. A. Reeb and N. C. Saunders, "Intraspecific Phylogeography: The Mitochondrial DNA Bridge between Population Genetics and Systematics," Annual Review of Ecolgy, Evolution, and Systematics, Vol. 18, No. 1, 1987, pp. 489-552.

[15] J. C. Avise, "Molecular Markers, Natural History, and Evolution," Chapman \& Hall, New York, 1994.

[16] J. C. Avise, "Phylogeography: The History and Formation of Species," Harvard University Press, Cambridge, 2000 .

[17] J. A. Doyle, "Phylogeny of Vascular Plants," Annual Review of Ecolgy, Evolution, and Systematics, Vol. 29, No. 1, 1998, pp. 567-599. doi:10.1146/annurev.ecolsys.29.1.567

[18] L. H. Rieseberg, J. Whitton and C. R. Linder, "Molecular Marker Incongruence in Plant Hybrid Zones and Phylogenetic Trees," Acta Botanica Neerlandica, Vol. 45, 1996, pp. 243-262.

[19] J. F. Wendel and J. J. Doyle, "Phylogenetic Incongruence: Window into Genome History and Molecular Evolution," In: P. S. Soltis, D. E. Soltis and J. J. Doyle, Eds., Molecular Systematics of Plants II, Kluwer, Dordrecht, 1998, pp. 265-296.

[20] B. G. Baldwin and S. Markos, "Phylogenetic Utility of the External Transcribed Spacer (ETS) of 18S-26S rDNA: Congruence of ETS and ITS Trees of Calycadenia (Com- 
positae)," Molecular Phylogenetics and Evoltion, Vol. 10, No. 3, 1998, pp. 449-463. doi:10.1006/mpev.1998.0545

[21] C. R. Linder, L. R. Goertzen, B. V. Heuvel, J. Francisco-Ortega and R. K. Jansen, "The External Transcribed Spacer of the Rdna Repeat: A New Nuclear Region for Low-Level Taxonomic Analysis of the Asteraceae and Closely Allied Families," Molecular Phylogenetics and Evoltion, Vol. 14, 2000, pp. 285-303. doi:10.1006/mpev.1999.0706

[22] S. Markos and B. G. Baldwin, "Higher-Level Relationships and Major Lineages of Lessingia (Compositae, Astereae) Based on Nuclear Rdna Internal and External Transcribed Spacers (ITS and ETS) Sequences," Systematic Botany, Vol. 26, No. 1, 2001, pp. 168-183.

[23] L. E. Urbatsch, R. P. Roberts and V. Karaman, "Phylogenetic Evaluation of Xylothamia, Gundlachia, and Related Genera (Asteraceae, Astereae) Based on Ets and Its Nrdna Sequence Data," American Journal of Botany, Vol. 90, No. 4, 2003, pp. 634-649. doi:10.3732/ajb.90.4.634

[24] O. Hidalgo, N. Garcia-Jacas, T. Garnatje and A. Susanna, "Phylogeny of Rhaponticum (Asteraceae, CardueaeCentaureinae) and Related Genera Inferred from Nuclear and Chloroplast DNA Sequence Data: Taxonomic and Biogeographic Implications," Annals of Botany, Vol. 97, No. 5, 2006, pp. 704-714. doi:10.1093/aob/mcl029

[25] M. Sato, K. Shimura and K. Hashizume, "Quality Valuation of Turmeric Powders on Market," Annual Report of Mie Prefecture Health and Enviromant Research Institute, Vol. 6, 2004, pp. 52-54.

[26] L. A. Jonson and D. E. Soltis, "matK DNA Sequences and Phylogenetic Reconstruction in Saxifragaceae s.str.," Systematic Botany, Vol. 19, No. 1, 1994, pp. 143-156. doi: $10.2307 / 2419718$

[27] J. R. Starr, S. A. Harris and D. A. Simpson, "Potential of the $5^{\prime}$ and 3 ' Ends of the Intergenic Spacer (IGS) of Rdna in the Cyperaceae: New Sequences for Lower-Level Phylogenies in Sedges with an Example from Uncinia Pers," Internat Journal of Plant Sciencese, Vol. 164, 2003, pp. 213-227. doi:10.1086/346168

[28] J. D. Thompson, D. G. Higgins and T. J. Gibson, "CLUSTAL W: Improving the Sensitivity of Progressive Multiple Sequence Alignment through Sequence Weighting, Positions-Specific Gap Penalties and Weight Matrix Choice," Nucleic Acids Research, Vol. 22, No. 22, 1994, pp. 4673-4680. doi:10.1093/nar/22.22.4673

[29] K. Tamura, J. Dudley, M. Nei and S. Kumar, "MEGA4: Molecular Evolutionary Genetics Analysis (MEGA) Software. Version 4.0," Molecular Biology and Evolution, Vol. 24, No. 8, 2007, pp. 1596-1599.

\section{doi:10.1093/molbev $/ \mathrm{msm} 092$}

[30] D. L. Swofford, "paup*. Phylogenetic Analysis Using Parsimony (*and Other Methods)," 4th Edition, Sinauer Associates, Sunderland, 2001.

[31] V. Grant, "Plant Speciation," Columbia University Press, New York, 1981.

[32] K. Marhold, J. Lihova, M. Perny, R. Grupeand and B. Neuffer, "Natural Hybridization in Cardamine (Brassicaceae) in the Pyrenees: Evidence from Morphological and Molecular Data," Botanical Journal of Linnean Society, Vol. 139, No. 3, 2002, pp. 275-294. doi:10.1046/j.1095-8339.2002.00066.x

[33] J. Yokoyama, T. Fukuda, A. Yokoyama and M. Maki, "The Intersectional Hybrid between Weigela hortensis and W. maximowiczii (Caprifoliaceae)," Botanical Journal of the Linnean Society, Vol. 138, No. 3, 2002, pp. 369-380. doi:10.1046/j.1095-8339.2002.00033.x

[34] H. Hayakawa, H. Hamachi, Y. Muramatsu, A. Hirata, Y. Minamiya, K. Matsuyama, K. Ito, J. Yokoyama and T. Fukuda, "Interspesific Hybridization between Arisaema sikokianum Franch. Et Savat. and A. tosaense Makino (Araceae) Revealed from Nuclear and Chloroplast DNA Comparisons," Acta Phytotaxonomica et Geobotanica, Vol. 61, No. 2, 2010, pp. 57-63.

[35] J. C. Avise, "Molecular Markers, Natural History, and Evolution," 2nd Edition, Sinauer Associates, Sunderland, 2004.

[36] Y. Katsuyama, M. Matsuzawa, N. Funa and S. Horiuchi, "In Vitro Synthesis of Curcumoids by Type III Polyketide Synthase from Oryza sativa," Journal of Biological Chemistry, Vol. 282, No. 52, 2007, pp. 37702-37709. doi:10.1074/jbc.M707569200

[37] Y. Katsuyama, T. Kita and S. Horiuchi, "Identification and Characterization of Multiple Curcumin Synthases from the Herb Curcuma longa," FEBS Letter, Vol. 583, No. 17, 2009, pp. 2799-2803. doi:10.1016/j.febslet.2009.07.029

[38] Y. Katsuyama, T. Kita, N. Funa and S. Horiuchi, "Curcumoid Biosynthesis by Two Type III Polyketide Synthases in the Herb Curcuma longa," Journal of Biological Chemistry, Vol. 284, No. 17, 2009, pp. 11160-11170. doi:10.1074/jbc.M900070200

[39] R. W. Allard, "Principle of Plant Breeding," Jhon Wiley and Sons, New York, 1960.

[40] M. King, "Species Evolution: The Role of Chromosome Change," Cambridge University Press, Melbourne, 1993.

[41] R. Dowkins, "Mechanism of Evolution," In: N. A. Campbell, J. B. Reece and L. G. Mitchell, Eds., Biology, 5th Edition, Addison Wesley Longman, Boston, 1999, pp. 412-487. 